\title{
GESTÃO AMBIENTAL DAS EMPRESAS BRASILEIRAS DE NAVEGAÇÃO E DOS PORTOS NACIONAIS QUE OPERAM NA HIDROVIA DO PARAGUAI-PARANÁ
}

\author{
The Environmental Management of Brazilian Navigation Companies and \\ National Ports That Operate on the Paraguay-Paraná Waterway
}

La Gestión Ambiental de las Empresas de Navegación Brasileñas y los Puertos Nacionales que Funcionan en la Hidrovia de Paraguay-Paraná

\author{
Samuel Ribeiro de Sousa* \\ Aguinaldo Silva** \\ *Universidade Federal de Mato Grosso do Sul - sarisosrs@gmail.com \\ **Universidade Federal de Mato Grosso do Sul - aguinaldo.silva@ufms.br
}

Recebido em 29/01/2020. Aceito para publicação em 17/03/2020
Versão online publicada em 05/05/2020 (http://seer.ufrgs.br/paraonde)

\section{Resumo:}

A Hidrovia do Paraguai-Paraná (HPP) constitui um dos mais importantes eixos fluviais de integração da América do Sul e vetor de desenvolvimento socioeconômico da região. Percorre cinco países (Brasil, Bolívia, Paraguai, Argentina e Uruguai) e sua utilização foi regulamentada pelo Acordo de Santa Cruz de La Sierra, que consagra, entre outros, os princípios de livre trânsito e de liberdade de navegação. Esse acordo permite o compartilhamento de território e de águas, redundando em alguns atritos. Nesse cenário conflituoso, ressalta-se a questão ambiental. A legislação brasileira é bem rígida com a proteção ao meio ambiente e estabelece diversos instrumentos e procedimentos destinados à preservação ambiental no âmbito das atividades econômicas potencialmente poluidoras. Dentre esses, merece destaque a gestão ambiental. Com este trabalho, buscou-se analisar, a partir de critérios objetivos, a eficiência da gestão ambiental das empresas brasileiras de navegação e dos portos nacionais que operam na HPP.

Palavras-chave: Gestão Ambiental. Fronteira. Hidrovia Paraguai-Paraná.

\begin{abstract}
:
The Paraguay-Paraná Waterway is one of the most important river routes of integration in South America and a vector of socioeconomic development in the region. It traveled through five countries (Brazil, Bolivia, Paraguay, Argentina and Uruguay) and its use was regulated by the Santa Cruz de La Sierra Agreement, which enshrines, among others, the principles of free transit and freedom of navigation. This agreement allows the sharing of territory and water by the signatories, resulting in some conflicts. In this conflictive scenario, the environmental issue is highlighted. The Brazilian legislation is very strict with the protection of the environment and establishes various instruments and procedures aimed at environmental preservation in the scope of potentially polluting economic activities. Among these, environmental management deserves special mention. The objective of this study was to analyze, from objective criteria, the environmental management efficiency of Brazilian shipping companies and the national ports operating on the Paraguay-Paraná Waterway.
\end{abstract}

Key-words: Environmental Management. Border. Paraguay-Paraná Waterway. 


\begin{abstract}
Resumen:
El Canal Paraguay-Paraná es una de las rutas de integración fluvial más importantes de América del Sur y un vector de desarrollo socioeconómico en la región. Viajó por cinco países (Brasil, Bolivia, Paraguay, Argentina y Uruguay) y su uso fue regulado por el Acuerdo de Santa Cruz de la Sierra, que consagra, entre otros, los principios del libre tránsito y la libertad de navegación. Este acuerdo permite que los firmantes compartan el territorio y el agua, lo que genera algunos conflictos. En este escenario conflictivo, se destaca el tema ambiental. La legislación brasileña es muy estricta con la protección del medio ambiente y establece diversos instrumentos y procedimientos destinados a la preservación del medio ambiente en el ámbito de las actividades económicas potencialmente contaminantes. Entre estos, la gestión ambiental merece una mención especial. El objetivo de este estudio fue analizar, desde criterios objetivos, la eficiencia de la gestión ambiental de las compañías navieras brasileñas y los puertos nacionales que operan en el Canal Paraguay-Paraná.
\end{abstract}

Palabras-clave: Gestión ambiental. Frontera. Canal Paraguay-Paraná.

\title{
1. Introdução
}

Ao longo da história, fronteiras foram estabelecidas com base em estruturas físicas distintivas do terreno em disputa, tais como rios e lagos; ou acidentes topográficos, como serras, montanhas ou picos elevados. Para as regiões em que não era possível aplicar esse procedimento demarcatório, utilizavam-se linhas geodésicas, que são linhas imaginárias traçadas no solo, referenciadas por coordenadas geográficas: paralelos e meridianos.

Os rios eram escolhidos como linha divisória entre países pela suposta facilidade na determinação do limite territorial, pois se pensava que haveria no curso das águas um traçado central constante. Esse entendimento, porém, não é verdadeiro. A ciência moderna tem mostrado que a trajetória do rio não é fixa, ela está em constante movimento, variando, embora de forma lenta, sua posição geográfica ao longo do tempo, alterando o desenho territorial dos Estados nacionais envolvidos. Essas distorções físico-naturais supervenientes, no entanto, ainda não foram equacionadas pelo Direito internacional no que se refere aos limites fronteiriços dos países.

O Rio Paraguai, além de atuar como limite fronteiriço entre Bolívia e Brasil, entre este e o Paraguai e entre este e a Argentina, constitui também, em conjunto com o Rio Paraná, a Hidrovia do Paraguai-Paraná (HPP), um dos mais importantes eixos fluviais de integração da América do Sul e vetor de desenvolvimento econômico e social dessa região, enquanto via de transporte aquaviário, propulsora do comércio entre as nações. A HPP percorre cinco países (Brasil, Bolívia, Paraguai, Argentina e Uruguai), iniciando na cidade de Cáceres-MT e terminando em Nova Palmira/Uruguai, conforme mostrado na figura 1.

ParaOnde!?, Porto Alegre, v.13, n.2, p.43-60, 2020.http://seer.ufrgs.br/paraonde Edição Especial - VII Seminário Internacional de Estudos Fronteriços 
Figura 1 - Hidrovia do Paraguai-Paraná.

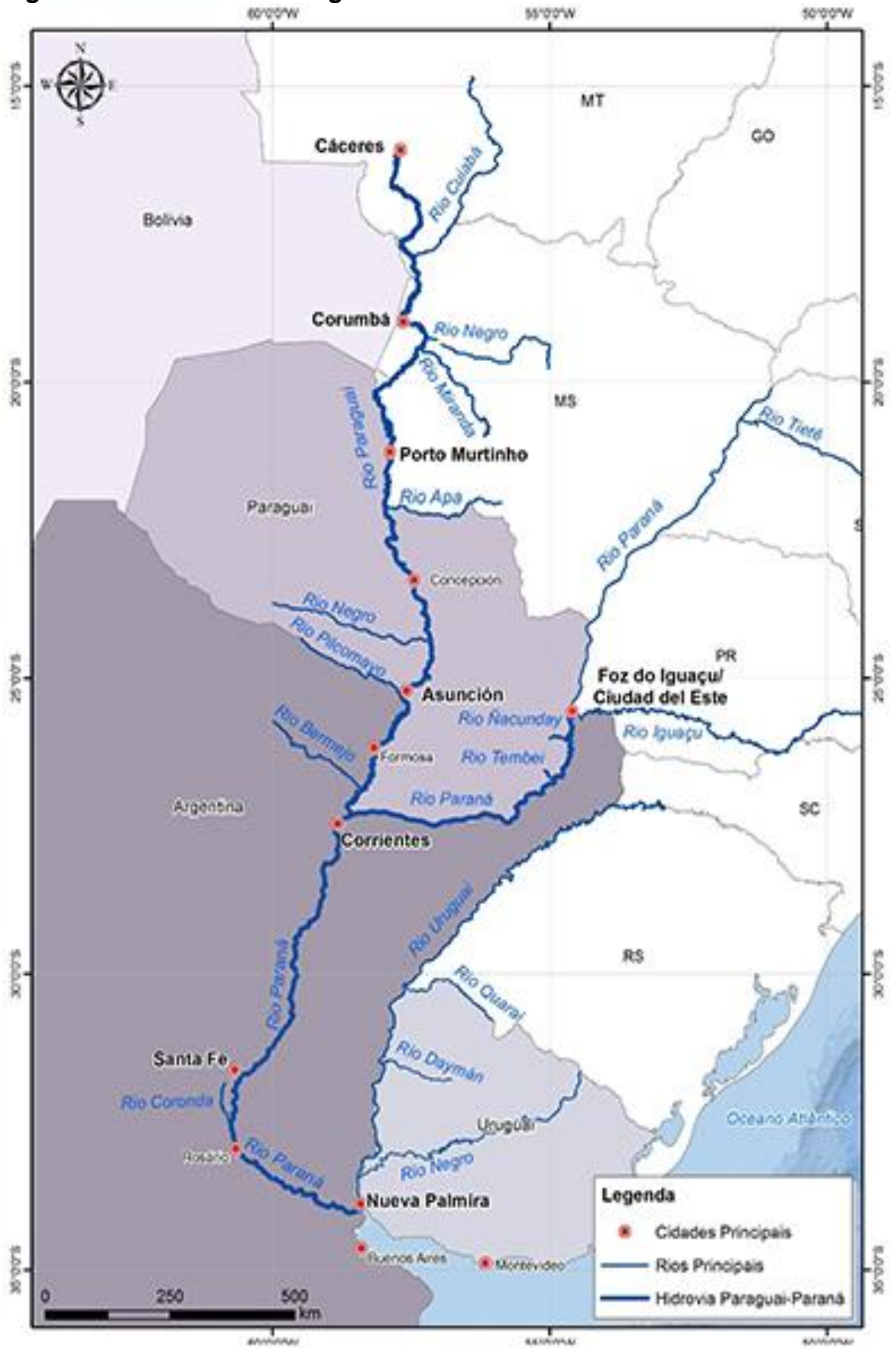

Fonte: UFPR

ParaOnde!?, Porto Alegre, v.13, n.2, p.43-60, 2020.http://seer.ufrgs.br/paraonde Edição Especial - VII Seminário Internacional de Estudos Fronteriços 
Com o intuito de regulamentar a utilização da HPP pelos países por ela cortados, foi assinado em Las Leñas (Argentina), em 26 de junho de 1992, o Acordo de Transporte Fluvial pela HPP, denominado Acordo de Santa Cruz de La Sierra (artigo 35), caracterizado como de natureza multilateral, com abrangência regional. Entrou em vigor em 12 de fevereiro de 1995, com duração inicial de dez anos (artigo 30), tendo sido prorrogado por mais 15 anos, nos termos do sétimo Protocolo Adicional, e foi promulgado pelo Brasil através do Decreto no 2.716, de 10/08/1998, publicado no Diário Oficial da União em 11/08/1998 (BRASIL, 1998).

Esse acordo e seus Protocolos adicionais consagram, entre outros, os princípios de livre trânsito e de liberdade de navegação. Isto é, de uma maneira geral, as empresas de quaisquer dos signatários podem operar livremente na HPP, sem restrições impostas unilateralmente por um país.

Por conseguinte, a HPP se tornou uma das mais importantes estruturas de integração social, política e econômica do Cone Sul, pois viabiliza o comercio em grande escala entre os signatários do Acordo de Santa Cruz de La Sierra e entre estes e outros países.

Convém destacar que a HPP, apesar de cortar cinco países sulamericanos, impõe-se como limite fronteiriço apenas entre Bolívia e Brasil (58 $\mathrm{km})$, entre este e o Paraguai $(322 \mathrm{~km})$ e entre este e a Argentina (390 km), formando pequena faixa de fronteira fluvial. No restante de sua extensão (2.672 $\mathrm{km})$, essa via de transporte tem, alternadamente, um único país em ambas as margens (UFPR/DNIT, 2015).

Portanto, seja quando atuando como limite fronteiriço, seja como via de transporte de envergadura internacional, a HPP se constitui área de compartilhamento de território.

Cabe salientar que o Acordo de Santa Cruz de La Sierra efetivamente permite não apenas o compartilhamento de território, mas também o de águas. Nessa seara, vem à tona um dos grandes problemas advindos desse uso compartilhado da HPP: a questão ambiental.

A Comissão Mundial sobre Meio Ambiente e Desenvolvimento, entidade ligada à Organização das Nações Unidas - ONU, definiu, em 1987, que crescimento sustentável é "o desenvolvimento que encontra as necessidades atuais sem comprometer a habilidade das futuras gerações de atender suas próprias necessidades" (A ONU, 2020).

Desse modo, é preciso equilíbrio entre o desenvolvimento econômico, a conservação ambiental, a justiça social, a qualidade de vida e o uso racional dos recursos naturais, em especial a água.

Tratando-se do Rio Paraguai, que corta territórios de riquíssima biodiversidade, a exemplo do Pantanal, buscar o crescimento econômico, através do uso da HPP, mantendo-se a obrigatória sintonia com a preservação do meio ambiente, é preceito fundamental.

$\mathrm{Na}$ legislação brasileira, a questão ambiental está bem consolidada, tendo essa temática caráter constitucional, na medida em que os fundamentos

ParaOnde!?, Porto Alegre, v.13, n.2, p.43-60, 2020.http://seer.ufrgs.br/paraonde Edição Especial - VII Seminário Internacional de Estudos Fronteriços 
e diretrizes da Política Nacional do meio ambiente se encontram esculpidos no próprio texto da Carta Magna vigente.

Nesse sentido, o artigo 225 da Constituição Federal de 1988 estabelecido que o meio ambiente ecologicamente equilibrado é direito fundamental das pessoas e que o Estado e a sociedade devem assegurá-lo às gerações presentes e futuras (BRASIL, 1988).

$\mathrm{Na}$ esfera infraconstitucional, há ainda vários diplomas legais e infralegais que estabelecem diversos mecanismos, instrumentos e procedimentos destinados à proteção ambiental no âmbito das atividades econômicas. Dentre esses, merece destaque a gestão ambiental.

A Resolução no 306/2002 do Conselho Nacional do Meio Ambiente CONAMA, órgão responsável pelo estabelecimento da Política Nacional do Meio Ambiente, define Gestão Ambiental como a "condução, direção e controle do uso dos recursos naturais, dos riscos ambientais e das emissões para o meio ambiente, por intermédio da implementação de um Sistema de Gestão Ambiental" (BRASIL, 2002).

Em relação especificamente aos portos, o órgão regulador da atividade portuária no Brasil, a Agência Nacional de Transportes Aquaviários - ANTAQ (2011, p. 61), entende que "uma adequada gestão ambiental portuária pode ser alcançada por meio da implantação de aprimoramento contínuo das conformidades ambientais, tanto aquelas previstas em lei como em outros dispositivos reguladores [...]".

Ainda segundo a ANTAQ (2011, p. 62/63), "A gestão ambiental estabelece as boas práticas ambientais na operação portuária, bem como para a Administração do Porto [...] deve ser uma ferramenta eficiente e efetiva de combate aos impactos ambientais [...]".

Quanto à navegação interior internacional, a legislação brasileira traz apenas a obrigação genérica de preservação do meio ambiente, não estabelecendo procedimentos detalhados de como proceder a proteção ambiental no âmbito dessa atividade.

Embora a navegação interior não esteja expressamente classificada na Lei $n^{\circ}$ 6.938/1981 como atividade efetiva ou potencialmente poluidora (BRASIL,1981), é plausível presumir, sem grandes dificuldades, que a prestação desse serviço de transporte traz em si potencial risco ao meio ambiente, tendo em vista que os veículos utilizados (barcaças e empurradores) trafegam sobre águas fluviais, estrutura natural altamente vulnerável à poluição, razão pela qual a gestão ambiental também se mostra imprescindível na condução dessa atividade econômica.

Este trabalho teve o objetivo de analisar, a partir de critérios objetivos, a gestão ambiental das empresas brasileiras de navegação (EBNs) e dos portos nacionais que operam na HPP.

Avaliou-se a eficiência do sistema de gestão ambiental implantado no âmbito das EBNs, que efetivamente estavam operando na HPP, e das instalações portuárias nacionais instaladas no trecho brasileiro da referida

ParaOnde!?, Porto Alegre, v.13, n.2, p.43-60, 2020.http://seer.ufrgs.br/paraonde Edição Especial - VII Seminário Internacional de Estudos Fronteriços 
hidrovia, as quais recebiam embarcações da navegação interior internacional.

\section{Desenvolvimento}

\section{Metodologia}

A avaliação da eficiência da gestão ambiental das EBNs e dos portos nacionais que operam na HPP foi feita através da análise de informações coletadas no banco de dados da ANTAQ, relativas às empresas brasileiras de navegação e às instalações portuárias públicas e privadas pesquisadas.

A população pesquisada foi o grupo formado pelas EBNs e pelos portos nacionais detentores de outorga da União, que os habilitam a operar na HPP.

Segundo informações colhidas no endereço eletrônico da ANTAQ (www.antaq.gov.br), órgão regulador da navegação interior internacional e da atividade portuária no Brasil, quatro empresas de navegação, três portos públicos e quatro terminais portuários privados estão legalmente habilitados a operar na HPP.

Por ocasião das pesquisas, constatou-se que dois portos públicos estão fora de operação há anos, de modo que eles foram excluídos do rol dos pesquisados.

Embora esteja em regular operação, o terceiro porto público também foi excluído da pesquisa porque não mais atende a navegação interior longitudinal de cargas, realizado na HPP. Por questões físico-operacionais, esse porto recebe atualmente somente as embarcações da navegação de turismo, que não faz parte do objeto deste estudo.

Um dos terminais portuários privados foi igualmente excluído, porquanto esta instalação portuária se encontra inoperante e a empresa exploradora já solicitou a renúncia de sua outorga junto à ANTAQ, mas o processo ainda não foi concluído.

Em resumo, após aplicados os critérios de exclusão, quais sejam: portos em efetiva operação na HPP e que atendem embarcações da navegação interior de percurso longitudinal internacional, restaram três instalações portuárias privadas, as quais estão destacadas na figura 2. 


\section{Figura 2: Portos pesquisados.}
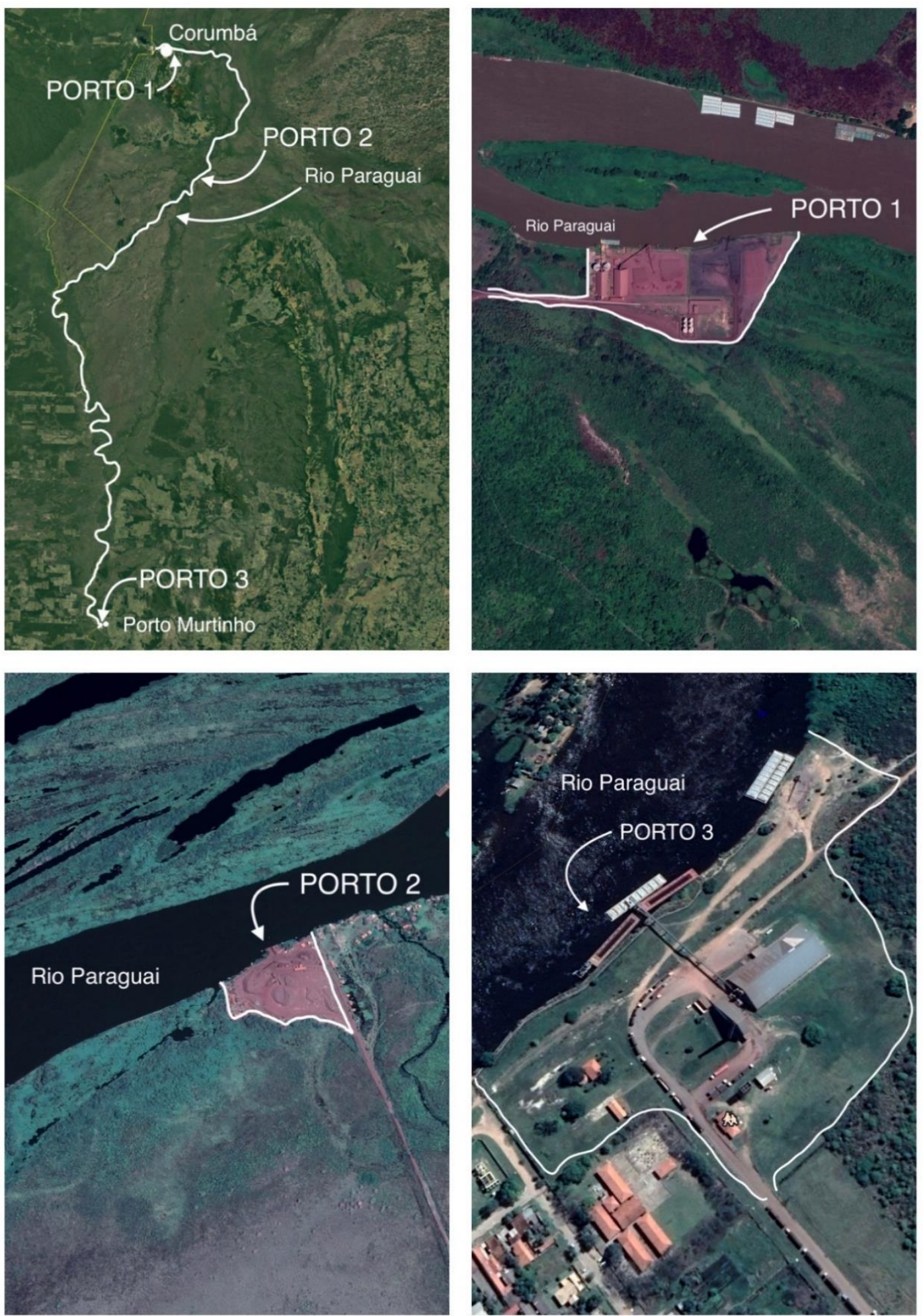

Fonte: Google Earth (Adaptado)

Isto é, foram pesquisados todos os agentes que estavam efetivamente operando na HPP (quatro EBNs e os três portos), com vistas a se obter maior precisão nos dados que foram coletados.

ParaOnde!?, Porto Alegre, v.13, n.2, p.43-60, 2020.http://seer.ufrgs.br/paraonde Edição Especial - VII Seminário Internacional de Estudos Fronteriços 
Embora tenham sido selecionados apenas terminais portuários privados, não houve prejuízos para a pesquisa, pois a legislação ambiental brasileira é igualmente válida tanto para as instalações privadas quanto para as públicas; bem como a ambas pode ser aplicada a metodologia de avaliação desenvolvida no âmbito deste trabalho.

As informações sobre as instalações portuárias pesquisadas foram coletadas na ANTAQ, na sua página oficial na internet (www.antaq.gov.br), dados públicos, e junto à Unidade Regional de Corumbá-MS (URECO), com a devida autorização da autoridade competente. Utilizou-se a base de dados relativos ao Índice de Desenvolvimento Ambiental (IDA) dos terminais portuários brasileiros, estabelecido pela agência reguladora dos portos.

O IDA é uma ferramenta de acompanhamento e controle da gestão ambiental das instalações portuárias brasileiras, desenvolvido pela ANTAQ em parceria com a Universidade de Brasília (UNB).

Segundo a ANTAQ, devido à diversidade e complexidade das questões ambientais envolvidas, o IDA foi construído com base em metodologia de análise multicritério, a saber: Processo de Análise Hierárquica (AHP - Analytic Hierarchy Process), considerada a mais adequada para aplicação em avaliação de desempenho ambiental (ÍNDICE, 2020).

Para a definição do IDA, foram criados quatorze indicadores globais, que se ramificam em trinta e oito indicadores específicos, os quais se subdividem em mais cento e sessenta subindicadores (atributos), distribuídos em quatro categorias (econômico-operacional, sociológico-cultural, físico-químico e biológico-ecológico), estabelecidos de acordo com a literatura técnica especializada e a legislação ambiental vigente no país, bem como se baseando em exemplos de procedimentos técnico-operacionais bem sucedidos, implementados em portos nacionais e internacionais.

Consta no endereço eletrônico da ANTAQ (www.antaq.gov.br) o IDA referente ao ano de 2018 de duas instalações portuárias pesquisadas. Porém, para as análises levadas a efeito neste trabalho, foi utilizada metodologia própria para todos os terminais estudados, com vistas à padronização dos processos avaliativos.

Para o cálculo do IDA/2018 das instalações portuárias pesquisadas neste trabalho, foram utilizados dados referentes aos indicadores específicos, coletados junto à URECO, aos quais foram atribuídos os valores da tabela constante no endereço eletrônico da ANTAQ (www.antaq.gov.br).

Foram utilizados, entre os trinta e oito indicadores específicos, aqueles aplicáveis ao tipo de instalação portuária pesquisada, de acordo com a classificação estabelecida pela Lei no 12.815/2013. No caso deste trabalho, Terminais de Uso Privado - TUP e Estação de Transbordo de Cargas - ETC (BRASIL, 2013).

Importa ressaltar, porém, que o peso dos subindicadores, que representam os graus de escalonamento do cumprimento dos indicadores específicos, não é divulgado pela ANTAQ. Em vista disso, o quantum de cada subindicador foi estipulado no âmbito deste trabalho, conforme sua relevância

ParaOnde!?, Porto Alegre, v.13, n.2, p.43-60, 2020.http://seer.ufrgs.br/paraonde Edição Especial - VII Seminário Internacional de Estudos Fronteriços 
ao objeto da pesquisa. Assim sendo, os resultados obtidos não necessariamente são os mesmos divulgados pela agência reguladora dos portos, que dispõe de metodologia específica.

Essa nova metodologia, estabelecida no âmbito deste trabalho, adaptada daquela utilizada pela ANTAQ, fez-se necessária porque a agência reguladora dos portos não divulga todos os dados necessários para que sua metodologia seja replicada pelo público em geral para o cálculo do IDA (falta o peso de cada subindicador/atributo) e não se localizou na literatura especializada outro método de avaliação disponível.

Quanto às empresas de navegação, as informações sobre elas, para uso neste trabalho, foram coletadas junto à ANTAQ e compiladas em formulário próprio, elaborado com base nos parâmetros utilizados pela própria agência reguladora dos portos para estabelecer o IDA das instalações portuárias brasileiras. Todavia, foram promovidas as adequações necessárias, levando-se em conta as características técnico-operacionais da atividade econômica estudada (navegação interior) e sua legislação de regência.

Tendo como referência os critérios para obtenção do IDA dos portos, definidos pela ANTAQ, fez-se uma adaptação destes para a navegação interior, criando-se parâmetros próprios, adequados a essa atividade. Nesse sentido, foram estabelecidos quatorze indicadores para avaliar a gestão ambiental das empresas de navegação.

A cada indicador atribuiu-se um peso e, ao final, fazendo a somatória, que pode variar de zero a cem, obtém-se o Índice de Desenvolvimento Ambiental da Navegação (IDAN). O peso dos indicadores, via de regra, é escalonado de acordo com o grau de atendimento do atributo.

Além disso, considerando que a ANTAQ não divulga uma classificação conceitual para o Índice de Desenvolvimento Ambiental das instalações portuárias nacionais, que pudesse ser utilizada como referência para esta pesquisa, criou-se também, no âmbito deste trabalho, com base nos valores obtidos no IDA e IDAN, um índice qualitativo para a gestão ambiental das empresas de navegação e dos portos pesquisados, nos termos da tabela 1.

Tabela 1 - Índice qualitativo para conceituação do IDA/IDAN.

\begin{tabular}{ll}
\hline \multicolumn{1}{c}{ PONTUAÇÃO (IDA/IDAN) } & \multicolumn{1}{c}{ CONCEITO } \\
\hline 0 a $40^{*}$ & PÉSSIMO \\
40 a $50^{*}$ & RUIM \\
50 a $60^{*}$ & REGULAR \\
60 a $80^{*}$ & BOM \\
80 a $90^{*}$ & ÓTIMO \\
90 a $100^{*}$ & EXCELENTE \\
\hline * Esses valores correspondem à porcentagem atingida em relação à \\
máxima possível.
\end{tabular}

O índice qualitativo tem o objetivo de melhorar a contextualização dos dados e facilitar o entendimento do valor do IDA / IDAN, sobretudo para o

ParaOnde!?, Porto Alegre, v.13, n.2, p.43-60, 2020.http://seer.ufrgs.br/paraonde Edição Especial - VII Seminário Internacional de Estudos Fronteriços 
público leigo, vez que é bem mais complexo interpretar apenas números, que comportam diversas interpretações e manipulações matemáticas.

Com fundamento nesses índices, quantitativo e qualitativo, foi avaliada a gestão ambiental das entidades pesquisadas.

Essa metodologia própria, criada para o cálculo do Índice de Desenvolvimento Ambiental das EBNs, é, em princípio, inédita, pois, no decorrer desse trabalho, não foi encontrada nenhuma outra que os órgãos ambientais ou reguladores competentes ou pesquisadores nacionais tenham desenvolvido com esse fim.

Cumpre ainda ressaltar que, por questões logísticas, foram pesquisadas somente empresas brasileiras de navegação interior internacional que, de fato, estavam operando na HPP; bem como os portos nacionais instalados no trecho brasileiro da referida hidrovia, os quais efetivamente recebiam embarcações empregadas na aludida navegação.

Contudo, considerando que as leis ambientais brasileiras estão entre as mais completas e avançadas do mundo (NOVAIS, 2017), as conclusões e recomendações referentes aos operadores brasileiros podem ser estendidas aos demais usuários estrangeiros da HPP.

\section{Resultados e Discussões}

$>$ Instalações Portuárias:

De acordo com os dados coletados junto à ANTAQ e incrementados no âmbito deste trabalho, estabeleceu-se o índice de desenvolvimento ambiental quantitativo e qualitativo das instalações portuárias nacionais em operação na HPP, conforme descrito na tabela 2:

\section{Tabela 2 - IDA das Instalações Portuárias}

\begin{tabular}{lcc}
\hline INSTALAÇÃO PORTUÁRIA & IDA & CONCEITO \\
\hline Terminal Portuário 1 & $79,11^{*}$ & BOM \\
Terminal Portuário 2 & $60,19^{*}$ & BOM \\
Terminal Portuário 3 & $63,94^{*}$ & BOM \\
\hline${ }^{*}$ Esses valores correspondem à porcentagem atingida em relação à \\
máxima possível. \\
Fonte: Autores.
\end{tabular}

Analisando os resultados apresentados na tabela 2, verifica-se que os terminais portuários pesquisados conseguiram IDA entre 60,19 e 79,11, atingindo um padrão qualitativo avaliado como BOM, razão pela qual se considera razoável a qualidade da gestão ambiental das instalações portuárias que operam na HPP, embora se repute necessária a implementação de melhorias nos procedimentos técnicos, administrativos e operacionais atuais, com vistas a que os portos alcancem maiores patamares no índice de desenvolvimento ambiental.

ParaOnde!?, Porto Alegre, v.13, n.2, p.43-60, 2020.http://seer.ufrgs.br/paraonde Edição Especial - VII Seminário Internacional de Estudos Fronteriços 
Pode-se atribuir os resultados obtidos à legislação ambiental vigente, aplicada às instalações portuárias, a qual, de maneira geral, já se encontra bem estabelecida e sedimentada no setor.

Além disso, há vários órgãos ambientais legalmente constituídos, trabalhando na fiscalização do cumprimento das normas ambientais vigentes no país.

Esses órgãos estão definidos no artigo 6ํ da Lei n 6.938/1981, a saber, os integrantes do Sistema Nacional do Meio Ambiente - SISNAMA, formado pelos órgãos e entidades da União, dos Estados, do Distrito Federal, dos Territórios e dos Municípios; bem como as fundações instituídas pelo Poder Público, responsáveis pela proteção e melhoria da qualidade ambiental (BRASIL, 1981); além da Marinha do Brasil, autoridade marítima do país (BRASIL, 1997).

Necessário se faz acrescentar nesse rol a ANTAQ, a qual, enquanto órgão regulador do setor portuário, criado pela Lei 10.233/2001, também detém a competência legal para atuar na preservação do meio ambiente (BRASIL, 2001).

Foi possível ainda identificar uma cultura de preservação ambiental já formada no setor portuário, fruto da incisiva atuação dos mencionados órgãos públicos, a qual contribui para a elevação do IDA das instalações portuárias pesquisadas.

\section{$>$ Empresas de Navegação:}

Com base nos dados coletados, definiu-se o índice de desenvolvimento ambiental quantitativo e qualitativo das empresas brasileiras de navegação interior internacional que operam na HPP, conforme a tabela 3.

\begin{tabular}{lcl}
\multicolumn{3}{l}{ Tabela 3 - Índice de desenvolvimento ambiental das EBNs pesquisadas. } \\
\hline EMPRESAS DE NAVEGAÇÃO & IDAN & CONCEITO \\
\hline EBN 1 & 21,42 & PÉSSIMO \\
EBN 2 & 32,13 & PÉSSIMO \\
EBN 3 & 52,36 & REGULAR \\
EBN 4 & 83,3 & ÓTIMO \\
\hline
\end{tabular}

Fonte: Autores.

Examinando os resultados obtidos na pesquisa em relação às empresas de navegação, infere-se que a gestão ambiental dessas entidades se encontra em níveis extremamente deficientes, salvo uma única exceção.

O índice de desenvolvimento ambiental das empresas pesquisadas apresentou valores muito baixos, situando-se, em sua maioria, em patamares qualitativos classificados como PÉSSIMO ou REGULAR, excetuando-se uma única EBN que atingiu grau ÓTIMO.

ParaOnde!?, Porto Alegre, v.13, n.2, p.43-60, 2020.http://seer.ufrgs.br/paraonde Edição Especial - VII Seminário Internacional de Estudos Fronteriços 
As prováveis causas identificadas para a problemática da baixa qualidade da gestão ambiental das empresas de navegação são:

- Falha na legislação

Ao contrário da legislação ambiental relativa aos portos, que é eficiente e já bem enraizada no exercício daquela atividade econômica, quando se trata da navegação interior, o arcabouço jurídico nacional é bem escasso, falho e insuficiente para proteger os recursos naturais afetados pela prestação desse serviço de transporte.

Um dos grandes equívocos da legislação ambiental em vigência no país é o fato de, no Anexo VIII da Lei $n^{\circ}$ 6.938/1981, não constar a navegação na relação das atividades classificadas como potencial ou efetivamente poluidoras (BRASIL, 1981).

No entanto, é razoavelmente presumível que essa atividade traz sim risco ao meio ambiente, uma vez que as embarcações operam na água, espaço natural fortemente suscetível à poluição.

No caso da navegação interior internacional, tratada neste trabalho, o problema é ainda mais grave, pois os rebocadores e barcaças são conduzidos durante longos períodos por águas fluviais, bem de imensurável valor para a vida, seja humana, vegetal ou animal.

Em função dessa omissão normativa, a legislação infralegal, editada pelos órgãos ambientais competentes, integrantes do SISNAMA, bem como a Marinha do Brasil e a ANTAQ, não estabelece rigorosas obrigações para as empresas de navegação no que tange à preservação do meio ambiente.

Nesse contexto, pode-se citar a desobrigação de licenciamento da atividade e de todas as demais exigências legais a ele associadas. Também não há previsão legal de as embarcações serem homologadas especificamente no aspecto ambiental, nem procedimento estabelecido para o tratamento dos resíduos sólidos e granéis líquidos, transportados ou produzidos a bordo dos veículos durante as viagens, etc.

Há, sem dúvida, uma excessiva liberdade normativa para o exercício da atividade de navegação interior no que diz respeito às questões ambientais, a despeito da imensa importância da preservação dos nossos recursos naturais, os quais são fortemente afetados por esse serviço de transporte.

- Falta de uma cultura de preservação ambiental arraigada no âmbito da atividade

Do ponto de vista histórico, a cultura de conservação do meio ambiente é bem recente, sobretudo no Brasil, onde a consciência da preservação ambiental ainda não ingressou satisfatoriamente em todos os setores da sociedade, principalmente nos econômicos.

Somente a partir do século passado é que se observou um efetivo fortalecimento das práticas de preservação ambiental em detrimento ao

ParaOnde!?, Porto Alegre, v.13, n.2, p.43-60, 2020.http://seer.ufrgs.br/paraonde Edição Especial - VII Seminário Internacional de Estudos Fronteriços 
crescimento econômico desordenado, que preponderava desde o início da revolução industrial, quando se buscava apenas produzir cada vez mais, com menores custos, sem a preocupação com o esgotamento dos recursos naturais utilizados.

A atuação mais firme dos estados nacionais e de organismos supranacionais, como a ONU e suas agências, bem como o engajamento de entidades da sociedade civil, como Organizações Não Governamentais (ONGs), redundou na elaboração de normas mais rigorosas de proteção ambiental e de políticas de conscientização em todos os setores da sociedade, visando à formação de uma cultura perene de preservação do meio ambiente no exercício das atividades econômicas.

No caso das empresas de navegação, a sedimentação da cultura de preservação ambiental é mais lenta porque a legislação de regência dessa atividade é bastante tímida, quase inócua no sentido de estabelecer obrigações que visem à conservação dos recursos naturais afetados pelo exercício desse serviço de transporte.

Dessa forma, é preciso uma atuação mais efetiva dos órgãos ambientais intervenientes na navegação interior, com vistas a se moldar nesse setor econômico uma cultura de preservação ambiental, implementada em sintonia com o desenvolvimento da atividade, possibilitando um crescimento econômico sustentável.

Esse processo é lento, gradativo, mas necessário. Envolve o estabelecimento de procedimentos e políticas que incentivem as empresas a adotarem ferramentas de proteção ao meio ambiente, entre elas, a gestão ambiental.

- Falta de conscientização sobre a necessidade da preservação ambiental

Há uma nítida necessidade de se criar no setor de navegação interior uma cultura de preservação do meio ambiente, a despeito das deficiências da legislação ambiental. Para tanto, é preciso conscientizar todos os atores envolvidos nessa atividade econômica, bem como seus usuários, para que passem a atuar como fiscais da preservação ambiental, exigindo das empresas que adotem políticas de conservação do meio ambiente como condição para o consumo dos seus produtos. No caso em análise, o serviço de transporte.

Vale frisar que não basta o estabelecimento de uma legislação mais rígida sem uma conscientização sobre a importância da preservação do meio ambiente. Se não houver a introspecção desse entendimento nos empresários, eles certamente buscarão meios para burlar a lei, com o intuito de se esquivar dos custos da implantação e manutenção do sistema de gestão ambiental.

Resta claro que apenas criar a lei não resolve o problema. Há um adágio popular, já incorporado inclusive no mundo jurídico, o qual diz que a lei boa é a que "pega", ou seja, aquela que as pessoas cumprem por vontade própria, pois entendem a importância dela.

ParaOnde!?, Porto Alegre, v.13, n.2, p.43-60, 2020.http://seer.ufrgs.br/paraonde Edição Especial - VII Seminário Internacional de Estudos Fronteriços 
Portanto, além de aperfeiçoar a legislação ambiental vigente no país, é preciso conscientizar as pessoas, físicas e jurídicas, incluindo as empresas de navegação, sobre a necessidade e a importância da preservação ambiental no setor de transporte aquaviário.

Todos os empreendimentos econômicos devem ter no âmago da atividade a premissa da conservação do meio ambiente em plena consonância com o desenvolvimento econômico da companhia. Com as empresas de navegação não pode ser diferente.

- Prioridade na redução dos custos e despesas

Para se manterem ativas no mercado globalizado, cada vez mais competitivo, as empresas precisam buscar a diminuição dos custos e o aumento dos lucros (SILVA, 2013). Entre as EBNs não é diferente.

Nessa perspectiva, procedimentos de preservação ambiental acabam sendo considerados como apenas uma despesa desnecessária, que pode ser descartada em nome do incremento dos ganhos econômicos.

Com efeito, do ponto de vista unicamente financeiro, é dispendioso implementar e manter um sistema de gestão ambiental. Entretanto, torna-se infinitamente mais caro degradar o meio ambiente, na medida em que se estará comprometendo o futuro das próximas gerações, o que, por si só, já justifica a adoção de medidas de proteção ambiental no âmbito das atividades econômicas.

Considerando a fragilidade da atual legislação ambiental brasileira em relação às empresas de navegação, incapaz de impor rigorosas obrigações de preservação do meio ambiente no setor de transporte aquaviário, essa prática de tratar a implementação de um sistema de gestão ambiental como gasto dispensável só poderá ser modificada com a consolidação de uma cultura de preservação dos recursos naturais afetados pela atividade, a ser alcançada pela conscientização dos empresários e usuários do serviço de transporte.

\section{Considerações finais}

A partir dos resultados obtidos na pesquisa, pode-se concluir que, de forma geral, é satisfatória a qualidade da gestão ambiental das instalações portuárias que operam na HPP, carecendo apenas de aperfeiçoamentos pontuais nos procedimentos técnicos, administrativos e operacionais atualmente utilizados, objetivando melhorar o desempenho no IDA.

No âmbito deste trabalho, os terminais portuários pesquisados atingiram IDA entre 63,19 e 79,11, alcançando um padrão qualitativo classificado como BOM.

Contribuíram para esse resultado o fato de a legislação ambiental que rege a atividade portuária brasileira já se encontrar bastante consolidada e de

ParaOnde!?, Porto Alegre, v.13, n.2, p.43-60, 2020.http://seer.ufrgs.br/paraonde Edição Especial - VII Seminário Internacional de Estudos Fronteriços 
existir diversos órgãos públicos, nas esferas federal, estadual e municipal, atuando na fiscalização do cumprimento das normas ambientais.

Além disso, identificou-se uma cultura de preservação ambiental já estabelecida no setor portuário, decorrente da legislação de regência bem estruturada e eficaz, bem como da intensa atuação dos órgãos ambientais integrantes do SISNAMA, da Marinha do Brasil e da ANTAQ, redundando na elevação do IDA das instalações portuárias pesquisadas.

Por outro lado, analisando os resultados obtidos na pesquisa em relação às empresas de navegação, infere-se que a gestão ambiental dessas entidades é bastante ineficiente, reclamando urgentes medidas para seu aprimoramento, com restruturação dos procedimentos técnicos, administrativos e operacionais em utilização, visando ao melhoramento do IDAN.

O índice de desenvolvimento ambiental das EBNs apresentou valores muito baixos, situando-se, em sua maioria, em níveis qualitativos classificados como PÉSSIMO ou REGULAR. Somente uma empresa atingiu o padrão ÓTIMO.

Foram identificadas quatro possíveis causas para a má qualidade da gestão ambiental das empresas de navegação:

a) Falha na legislação, sobretudo pela não classificação da navegação como atividade potencialmente poluidora, redundando em normas infralegais, editadas pelos órgãos ambientais competentes, pouco rigorosas, ineficientes para coibir danos aos recursos naturais afetados pela prestação desse serviço de transporte;

b) Falta de uma cultura de preservação do meio ambiente arraigada no âmbito da atividade de navegação, em função da legislação ambiental ainda incipiente e da tímida atuação dos órgãos públicos competentes nesse setor econômico;

c) Falta de conscientização dos exploradores da navegação interior sobre a necessidade da preservação ambiental no âmbito dessa atividade, com vistas à conservação dos recursos naturais afetados pela prestação desse serviço de transporte;

d) Prioridade dada pelas empresas de navegação para a redução dos custos e despesas em detrimento do investimento na implantação e manutenção de um sistema de gestão ambiental da atividade, tendo em vista que as companhias, de uma maneira geral, estão inseridas num ambiente econômico onde o ganho financeiro prevalece sobre a preocupação com a garantia da sobrevivência das futuras gerações.

Convém observar que essas causas se autocompletam e se afetam mutuamente, pois as falhas na legislação impedem que os órgãos ambientais atuem com mais firmeza na preservação ambiental no âmbito da navegação interior e essa atuação estatal deficitária contribui para a não sedimentação de

ParaOnde!?, Porto Alegre, v.13, n.2, p.43-60, 2020.http://seer.ufrgs.br/paraonde Edição Especial - VII Seminário Internacional de Estudos Fronteriços 
uma cultura de preservação do meio ambiente, pois esta deve ser construída paulatinamente ao longo do tempo; bem como não favorece a formação de uma conscientização nos empreendedores sobre a necessidade de conservação dos recursos naturais afetados pelo exercício do transporte aquaviário.

Esse ciclo vicioso resulta invariavelmente numa clara ineficiência da gestão ambiental das EBNs atuantes na HPP.

Para solucionar a má qualidade da gestão ambiental das empresas de navegação que operam na HPP, sugere-se:

I- Mudanças na legislação ambiental em vigência no país para tornar mais rígido o controle da navegação interior, no que se refere à preservação do meio ambiente, alterando o Anexo VIII da Lei $n^{\circ} 6.938 / 1981$ no intuito de inserir a navegação no rol das atividades consideradas potencialmente poluidoras, bem como a edição de normas infralegais, a serem baixadas pelos órgãos ambientais competentes, contendo a imposição de mecanismos de gestão ambiental para as empresas de navegação, notadamente quanto a licenciamento ambiental específico para a prestação desse serviço de transporte, a tratamento dos resíduos sólidos e os granéis líquidos, sejam os transportados ou aqueles produzidos a bordo das próprias embarcações durante as viagens, e o devido descarte desses materiais, entre outras obrigações;

II- Atuação mais incisiva dos órgãos públicos competentes, integrantes do SISNAMA, Marinha do Brasil e ANTAQ, no sentido de fazer cumprir a legislação ambiental no âmbito da atividade de navegação, criando, assim, paulatinamente, uma cultura de conservação do meio ambiente no seio da atividade de navegação interior;

III- Conscientização das empresas de navegação interior sobre a importância da conservação do meio ambiente do âmbito de suas atividades através de campanhas educativas e outras medidas pedagógicas com esse fim, integrando nessa luta o usuário do serviço de transporte para que atuem como fiscais da preservação ambiental, obrigando as companhias a desenvolverem práticas sustentáveis no ramo econômico de atuação delas;

IV- Alteração do Acordo de Transporte Fluvial pela HPP no sentido de fazer constar explicitamente no documento oficial cláusula que imponha às empresas de navegação de todos os países signatários a obrigação de implantar no âmbito de suas atividades a gestão ambiental.

\section{Referências}

A ONU e o Meio Ambiente. Nações Unidas Brasil, 2020. Disponível em: <https://nacoesunidas.org/acao/meio-ambiente/>. Acesso em: 27 jan. 2020.

BRASIL. Constituição da República Federativa do Brasil. Senado Federal. Brasília - DF, 1988.

ParaOnde!?, Porto Alegre, v.13, n.2, p.43-60, 2020.http://seer.ufrgs.br/paraonde Edição Especial - VII Seminário Internacional de Estudos Fronteriços 
. Agência Nacional de Transportes Aquaviários (ANTAQ). Porto Verde: Modelo Ambiental Portuário. 2011. Disponível em: < http://web.antaq.gov.br/Portal/pdf/PortoVerde.pdf>. Acesso em: 30 ago. 2018.

. Conselho Nacional do Meio Ambiente. Resolução CONAMA n 306, de 5 de julho de 2002 Diário Oficial da União, Poder Executivo, Brasília, DF, 13 jul. 2002. Seção 1, páginas 75-76.

Decreto $\mathrm{n}^{\circ}$ 2.716, de 10 de agosto de 1998. Promulga o Acordo de Transporte Fluvial pela Hidrovia Paraguai-Paraná (Porto de Cáceres/Porto de Nova Palmira). Diário Oficial da União, Poder Executivo, Brasília, DF, 11 ago. 1998.

. Lei no 6.938, de 31 de agosto de 1981. Dispõe sobre a Política Nacional do Meio Ambiente, seus fins e mecanismos de formulação e aplicação, e dá outras providências. Diário Oficial da União, Poder Executivo, Brasília, DF, 02 nov. 1981. 1998.

. Lei no 9.537, de 11 de dezembro de 1997. Dispõe sobre a segurança do tráfego aquaviário em águas sob jurisdição nacional e dá outras providências. Diário Oficial da União, Poder Executivo, Brasília, DF, 12 dez. 1997.

. Lei no 9.905, de 12 de fevereiro de 1998. Dispõe sobre as sanções penais e administrativas derivadas de condutas e atividades lesivas ao meio ambiente, e dá outras providências. Diário Oficial da União, Poder Executivo, Brasília, DF, 17 fev. 1998.

. Lei $n^{\circ} 10.233$, de 05 de junho de 2001. Dispõe sobre a reestruturação dos transportes aquaviário e terrestre, cria o Conselho Nacional de Integração de Políticas de Transporte, a Agência Nacional de Transportes Terrestres, a Agência Nacional de Transportes Aquaviários e o Departamento Nacional de Infra-Estrutura de Transportes, e dá outras providências. Diário Oficial da União, Poder Executivo, Brasília, DF, 06 de jun. 2001.

Lei $n^{\circ} 12.815$, de 05 de junho de 2013. Dispõe sobre a exploração direta e indireta pela União de portos e instalações portuárias e sobre as atividades desempenhadas pelos operadores portuários [...].e dá outras providências. Diário Oficial da União, Poder Executivo, Brasília, DF, 05 de jun. 2013 - Edição Extra.

ÍNDICE de Desenvolvimento Ambiental. Agência Nacional de Transportes Aquaviários (ANTAQ), 2020. Disponível em:

$<$ http://portal.antaq.gov.br/index.php/meio-ambiente/indice-de-desempenhoambiental/>. Acesso em: 27 jan. 2020.

NOVAIS, Vânia Mendes da Silva. Desafios para uma efetiva gestão ambiental no Brasil. IFPA. Belém, 2017. Disponível em:

<http://www.conceicaodoaraguaia.ifpa.edu.br/docman/editais/posga2017/1322texto-i/file>. Acesso em 31 dez. 2019.

SILVA, Valéria Gomes da. Modelo Fuzzy como uma Ferramenta de Redução da Subjetividade de Apuração de Custos pelo TDABC. Dissertação de

ParaOnde!?, Porto Alegre, v.13, n.2, p.43-60, 2020.http://seer.ufrgs.br/paraonde Edição Especial - VII Seminário Internacional de Estudos Fronteriços 
Mestrado - Universidade Federal do Rio Grande do Sul. Faculdade de Ciências Econômicas. Porto Alegre, 2013. Disponível em: < https://www.lume.ufrgs.br/handle/10183/96688 >. Acesso em 02 jan. 2020.

UFPR - Universidade Federal do Paraná; DNIT - Departamento Nacional de Infraestrutura de Transportes. Hidrovia do Rio Paraguai: Estudo de Viabilidade Técnica, Econômica e Ambiental: Relatório do Estudo - EVTEA / Instituto Tecnológico de Transportes e Infraestrutura. - Curitiba: UFPR/ITTI, 2015. 